India and elsewhere. It is hoped that these monographs will eventually provide a source of material to be used in the preparation of Indian botanical text-books.

The present volume deals systematically with the numerous common aquatic flowering plants of India, and in addition to descriptive matter provides keys for their identification at family, generic and species levels. The characteristics of the Indian climate are such that many plants which grow during the monsoon season could well be classed as aquatic plants, since the soil in which they grow is often immersed in some depth of water; however, in the interests of brevity the author has excluded both monsoon and mangrove plants from his treatise.

Although they contain much interesting information, on the whole the descriptions of the various species are somewhat dull; however, the book will no doubt be used principally as a work of reference. The text is sprinkled with numerous botanical terms, some of which are not in common usage, and the provision of a glossary might have been helpful. In providing morphological, anatomical and especially embryological information about the species described, where this is available, the author has drawn largely from Indian literature. The pharmaceutical and other economic uses of the plants are also given, where appropriate, and this information is interesting and sometimes surprising; aquatic plants are utilized in numerous ways, both as medicaments and in the manufacture of articles such as sun hats. A useful appendix supplies the chromosome numbers of many of the plants described.

This well-produced book is illustrated with many clear line-drawings and a few photographs; the latter are of rather indifferent quality and add little to the value of the text. The usefulness of the line drawings would probably have been increased by the provision of scales of magnification, which are supplied in only some instances. With a few exceptions, the text seems to be largely free from errors.

As a systematic work, the present volume appears to fulfil its purpose admirably; it will provide a very useful addition to Indian botanical literature, and to the literature of aquatic plants in general. No description of a Flora which can claim several representatives of such fascinating families as the Podostemaceae could fail to interest the morphologist as well as the systematist; it is to be hoped that this book will stimulate the further investigation of aquatic angiosperms in all their aspects.

Elizabeth G. Cutter

\section{THE ROYAL ARMY VETERINARY CORPS}

The History of The Royal Army Veterinary Corps 1919-1961. By Brigadier J. Clabby. Pp. $244+56$ photographs. (London: J. and A. Allen and Co., 1963.) $50 s$.

7 HE history of the British Army Veterinary Services in the First World War (History of the Great War: Veterinary Services, by Blenkinsop and Rainey, London; H.M.S.O., 1925) is now succeeded by a history bringing the story up to 1961 .

It is of interest to compare tho outlook and methods in the two Wars, one before the mechanized age had got into its stride and the other after the general public had ceased to regard animals as of importance for military purposes oxcept for food. Again, it is of interest to consider the recently issued history of the U.S. Army veterinary services (Nature, 198, 822; 1963.) It could be said that the British histories follow a rather typical, amateur-sounding trend, very enterprising and perhaps rather personal. and with some hankering after the old days of the horse and even the camel. On the other hand, the American account is very impersonal, efficient, bustling and very well planned. The achievements of both countries in military veterinary service in the First World War were outstandingly good.

By 1939 cavalry had disappeared as such and the artillery services and most of the former pack transport had been mechanized; army veterinary officers had seen the red light and found civilian careers on a large scale. Actually horses and mules found a place in operations to a much greater extent than could be anticipated and were of much importance in certain spheres in Italy, Africa and Asia. Considerable numbers were captured from the Italians in Africa and taken over in the ensuing opera. tions.

Bizarre new problems had to be met. Mules were dropped from aeroplanes by parachute. In Wingate's Chindit force mules were a serious handicap to his troops when penetrating enemy country because of their braying, which warned the enemy and was a danger to morale. At relatively short notice mules were 'devoiced' and dispatched as replacements. This involved a surgical operation on the vocal cords and a special scheme for the procedure on a large scale had to be devised hurriedly and without previous experience of what surgical interference was required to achieve the desired results.

Most of the book is devoted to detailed accounts of the work done and systems followed in the five widely separated theatres of war.

This is an arresting book which will be of interest to all concerned with riding, draft and pack animals in particular and with all aspects of animal life. In war, animals have, unfortunately, increased dangers from many sources, and cruelty and even pain not related to cruelty. The army veterinary services are very active in measures to prevent unnecessary suffering. A hazard to the animal that has always accompanied war is when persons unaccustomed to animals are drafted to animal units; in the Second World War this was a very common occurrence because, by then, so few persons had experience with horses. Many loved the job and did it well, but others were probably disappointed in a non-mechanical duty and not very efficient. Mules reported to be vicious were found on occasion to be underworked and overfed: in any event for a tyro to be placed in charge of an army mule could be described as an experience.

A surprise was that the Japanese did not understand surra in horses; it is not serious in cattle, but they are carriers of the trypanosome concerned, and they thought that it could be ignored in the horses. From their known interest in Burma before the War it would not have been expected that their observers had slipped up in such a fashion.

War dogs really came into their own in the Second World War. It is a serious failure that their value was not recognized in earlier days. There was plenty of evidence of the reliability, after the right training and in the right hands, of suitable dogs for certain very intricate work. Survival of a medieval outlook may have tempered the judgment of war lords. As infantry patrol aids, guards, messengers in certain types of country, for finding casualties and even for finding buried caches of arms and for mine detection they have value. An illustration shows a dog with a rifle that it had found in a concealed position.

In modern war there is important linkage with civil services, air raid and bomb precautions, Animals of all kinds require service, as hazards to the human population, as well as for veterinary attention. With the importance of war gases, missile damage, fall-out, etc. the animal side requires special attention and the army veterinary services are trained accordingly.

The book is full of interesting illustrations and is well written and produced. 